\title{
Long-term excess mortality after chronic subdural hematoma
}

\author{
Minna Rauhala ${ }^{1}$ Pauli Helén ${ }^{1} \cdot$ Karri Seppä ${ }^{2} \cdot$ Heini Huhtala ${ }^{3} \cdot$ Grant L. Iverson $^{4,5,6} \cdot$ Tero Niskakangas $^{1}$. \\ Juha Öhman ${ }^{7} \cdot$ Teemu M. Luoto ${ }^{1}$
}

Received: 9 January 2020 / Accepted: 26 February 2020 / Published online: 7 March 2020

(C) The Author(s) 2020

\begin{abstract}
Objective To assess possible long-term excess mortality and causes of death of patients with chronic subdural hematoma (CSDH). Methods A retrospective study (1990-2015) of adult patients $(n=1133$, median age $=76$ years old, men $=65 \%)$ with CSDH identified by ICD-codes and verified by medical records. All patients were followed until death or the end of 2017. Cumulative relative survival ratios and relative excess risks of death (RER) were estimated by comparing patients' mortality with that in the entire regional matched population. The causes of death were compared with a separate reference group formed by randomly choosing sex, age, and calendar time matched controls (4 controls per each CSDH patient).

Results The median follow-up time was 4.8 years (range $=0-27$ years), and $710(63 \%)$ of the patients died (median age at death $=84$ years old). The cumulative excess mortality was 1 year $=9 \%, 5$ years $=18 \%, 10$ years $=27 \%$, 15 years $=37 \%$, and 20 years $=48 \%$. A subgroup of CSDH patients $(n=206)$ with no comorbidity had no excess mortality. Excess mortality was related to poor modified Rankin score at admission $(\mathrm{RER}=4.93)$ and at discharge $(\mathrm{RER}=8.31)$, alcohol abuse $(\mathrm{RER}=4.47)$, warfarin $(\mathrm{RER}=2.94)$, age $\geq 80$ years old $(\mathrm{RER}=1.83)$, non-operative treatment $(\mathrm{RER}=1.56)$, and non-traumatic etiology $($ RER $=1.69)$. Hematoma characteristics or recurrence were unrelated to excess mortality. Dementia was the most common cause of death among the CSDH patients $(21 \%)$ and the third most common cause in the reference group $(15 \%, p<0.001)$.

Conclusions Patients with CSDH have continuous excess mortality up to 20 years after diagnosis. Patient-related characteristics have a strong association with excess mortality, whereas specific CSDH-related findings do not. CSDH patients have an increased risk for dementia-related mortality.
\end{abstract}

Keywords Subdural hematoma, chronic $\cdot$ Mortality, excess $\cdot$ Causes of death $\cdot$ Survival $\cdot$ Mortality, excess

\section{Introduction}

Chronic subdural hematoma (CSDH) is a common disease in neurosurgical practice among elderly patients $[1,3,27]$. The reported annual incidence of CSDH has ranged widely across studies, from 1.7 to 20.6 per 100,000 - and the overall incidence is increasing as the global population becomes progressively older [38]. In a prior study using this same patient

This article is part of the Topical Collection on Brain trauma

Previous Presentations: The abstract of this manuscript has been presented at the EANS 2019 meeting (Dublin, Ireland, September 24 28, 2019).

Minna Rauhala

minna.j.rauhala@pshp.fi

1 Department of Neurosurgery, Tampere University Hospital and Tampere University, Tampere, Finland

2 Finnish Cancer Registry, Institute for Statistical and Epidemiological Cancer Research, Helsinki, Finland

3 Faculty of Social Sciences, Biostatistics Group, Tampere University, Tampere, Finland
4 Department of Physical Medicine and Rehabilitation, Harvard Medical School, Boston, MA, USA

5 Spaulding Rehabilitation Hospital and Spaulding Research Institute, Boston, MA, USA

6 Home Base, A Red Sox Foundation and Massachusetts General Hospital Program, Boston, MA, USA

7 Faculty of Medicine and Life Sciences, Tampere University, Tampere, Finland 
cohort, we reported that during a 26-year period between 1990 and 2015, the overall incidence doubled from 8.2 to 17.6 / 100,000/year in the Pirkanmaa region, Finland [32]. The incidence per 100,000 person-years remained quite stable among adults younger than 70 years, whereas the incidence nearly tripled among the population 80 years or older. The global population of people aged 80 and older is expected to more than triple between 2015 and 2050 [17]. Consequently, CSDH is a condition of growing importance.

CSDH has been considered to be relatively benign, but during the last years, it has been recognized to have worse outcome than earlier assumed [11, 25, 29]. It has been speculated that CSDH may be a sentinel health event, and a harbinger of subsequent morbidity and mortality [3, 11, 29]. Agerelated brain degeneration with an enlarging potential subdural space is assumed to be an important risk factor for CSDH [22, 24, 37]. Conversely, CSDH itself has been associated with a significant increase in the degree of brain atrophy post-CSDH [4]. Other well-known risk factors for $\mathrm{CSDH}$ are trauma [26], alcohol overuse [28], and antithrombotic therapy $[6,15,23,30]$.

Reported mortality rates after CSDH vary widely across studies, and a 1-year mortality rate of up to $32 \%$ has been reported [29]. In general, CSDH patients are from an age group with high baseline expected mortality. It is not possible to draw reliable conclusions on the excess mortality related to CSDH without comparing these patients to a matched sample from the general population. To date, only four studies (Table 1) have compared mortality after $\mathrm{CSDH}$ with anticipated survival $[11,16,25,29]$. All of these studies have shown varied excess mortality, but the follow-up periods have extended only up to 8 years. Furthermore, there are no prior studies reporting long-term mortality in CSDH patients compared with a matched sample from the general population in an unselected, population-based series. Additionally, only two studies have previously reported the causes of death after a diagnosis of CSDH [19, 25].

The objective of this study was to examine the possible long-term excess mortality related to $\mathrm{CSDH}$, and the causes of death after a diagnosed CSDH. A large unselected, population-based CSDH patient cohort was compared with the general population from the same region, matched by sex, age, and calendar time. The causes of death of the $\mathrm{CSDH}$ patients were compared with a separate matched reference group.

\section{Methods}

\section{Material and ethical aspects}

The study was conducted in the Department of Neurosurgery at the Tampere University Hospital (Tampere, Finland). All adult patients ( $\geq 18$ years old Pirkanmaa residents) with a diagnosis of CSDH between 1990 and 2015 were retrospectively identified using the hospital's patient administrative databases. The cases were identified using International Classification of Diseases (ICD) codes for traumatic and non-traumatic subdural hematomas (SDHs). Verified cases were classified by SDH type (acute, subacute, chronic, and hygroma) by reviewing all the medical records. Exclusion criteria were acute or subacute SDH $(<3$ weeks after head trauma), hygroma (a collection of subdural cerebrospinal fluid without any signs of blood), and any form of intracranial surgery within 12 months preceding the CSDH diagnosis.

The dates and causes of deaths were obtained from Statistics Finland (Helsinki, Finland). The Finnish official cause of death statistics are, in practice, $100 \%$ complete in relation to the cause and date of death. The entire Pirkanmaa population matched by sex, age, and calendar time was used for the excess mortality analysis. For the cause of death comparison, a separate reference group was formed by randomly choosing 4:1 sex, age ( \pm 6 months), and calendar timematched control subjects from Pirkanmaa for each CSDH patient. The reference group $(n=4532)$ was obtained from the Statistics Finland.

The Pirkanmaa region is a geographically well-defined area with both rural and urban areas that holds one of Finland's five neurosurgical departments (Department of Neurosurgery, Tampere University Hospital, Tampere, Finland). All neurosurgical cases of the Pirkanmaa region are referred to the Tampere University Hospital. Over 9\% of the Finnish population lives in the Pirkanmaa region. The population increased from 427,223 in 1990 to 506,114 in 2015 . The population over 80 years old has almost doubled from 13,565 to 26,417 during the study period.

\section{Data collection}

A detailed and structured data collection was performed from medical records. CT scans or MR images were not separately inspected. Patients were stratified into three groups according to age:(1) 18-59 years, (2) 60-79 years, and (3) $\geq 80$ years. The age categories were formed a priori on the basis of previous literature, convenience and the ease of presenting the results. The data collection included the following: comorbidities, medication, possible trauma, symptoms, neurological condition assessments based on both the Glasgow Coma Scale (GCS) and the modified Rankin Scale (mRS) score at admission, and for the operative group also at discharge. CSDH-related findings collected were localization (unilater$\mathrm{al} / \mathrm{bilateral}$ ) and hematoma thickness divided into three groups ( $\leq 15 \mathrm{~mm}, 16-25 \mathrm{~mm}$, and $>25 \mathrm{~mm}$ ) selected before the data collection was started. Operation details were collected. $\mathrm{CSDH}$ recurrence was defined as an ipsilateral hematoma 
Table 1 Summary of studies on long-term excess mortality in chronic subdural hematoma patients

\begin{tabular}{|c|c|c|c|c|c|c|c|c|c|}
\hline \multirow[t]{2}{*}{ Authors } & \multirow[t]{2}{*}{ Country } & \multirow{2}{*}{$\begin{array}{l}\text { Time } \\
\text { period }\end{array}$} & \multirow[t]{2}{*}{$n$} & \multirow{2}{*}{$\begin{array}{l}\text { Age mean, y } \\
\text { (range) }\end{array}$} & \multirow{2}{*}{$\begin{array}{l}\text { Follow-up } \\
\text { period median, } \\
\text { y (range for } \\
\text { survivors) }\end{array}$} & \multicolumn{2}{|l|}{ Mortality (\%) } & \multirow[t]{2}{*}{ Control data } & \multirow[t]{2}{*}{ Excess mortality } \\
\hline & & & & & & 6 months & 1 year & & \\
\hline $\begin{array}{l}\text { Miranda } \\
\text { et al. } \\
2011^{7}\end{array}$ & USA & 2000-2008 & 209 & $80.6(65-96)$ & 1.45 (N/A-8.3) & 26.3 & 32 & $\begin{array}{l}\text { Center of Disease } \\
\text { Control and } \\
\text { Prevention data }\end{array}$ & $\begin{array}{l}\text { - Excess mortality up } \\
\text { to } 1 \text { year beyond } \\
\text { diagnosis } \\
\text { - Median survival: } \\
\text { o CSDH } 4.4 \text { year } \\
\text { o Anticipated } \\
\text { actuarial survival } \\
6 \text { year }\end{array}$ \\
\hline $\begin{array}{l}\text { Dumont } \\
\text { et al. } \\
2013^{8}\end{array}$ & USA & 1996-2010 & 287 & 75 (55-N/A) & $2.3(0.5-14)$ & N/A & 30 & $\begin{array}{l}\text { Center of Disease } \\
\text { Control and } \\
\text { Prevention data }\end{array}$ & $\begin{array}{l}-1 \text { year standardized } \\
\text { mortality ratio: } \\
\text { o } 55-64 \text { years: } 17 \\
\text { o } 65-74 \text { years: } 8.1 \\
\text { o } 75-84 \text { years: } 3.4 \\
\text { o } \geq 85 \text { years: } 2.9 \\
\text { - Median survival: } \\
4.0 \pm 0.5 y\end{array}$ \\
\hline $\begin{array}{l}\text { Manickam } \\
\text { et al. } \\
2016^{9}\end{array}$ & Australia & 2006-2011 & 155 & $69.3(18-\mathrm{N} / \mathrm{A})$ & $\begin{array}{l}5.2 \\
(\mathrm{~N} / \mathrm{A}-14.19)\end{array}$ & 14.19 & 20.35 & $\begin{array}{l}\text { Australian Bureau of } \\
\text { Statistics, and the } \\
\text { Registry of Births, } \\
\text { Deaths and } \\
\text { Marriages }\end{array}$ & $\begin{array}{l}\text { - Excess mortality } \\
\text { throughout } \\
\text { follow-up. } \\
\text { - Average long-term } \\
\text { survival: } \\
\text { o CSDH: } \\
5.29 \pm 0.59 \text { year } \\
\text { o Actuarial data: } \\
17.74 \pm 1.8 \text { year }\end{array}$ \\
\hline $\begin{array}{l}\text { Guilfoyle } \\
\text { et al. } \\
2017^{19}\end{array}$ & UK & 2004-2007 & 215 & $78(35-95)$ & N/A (8-10) & $\begin{array}{l}\text { Drain group: } 8.6 \\
\text { No drain } \\
\text { group: } \\
18.1\end{array}$ & N/A & $\begin{array}{l}\text { Cohorts of the general } \\
\text { population with the } \\
\text { same number of } \\
\text { cases and identical } \\
\text { age and sex profiles } \\
\text { as the drain and no } \\
\text { drain groups } \\
\text { (Human Mortality } \\
\text { Database) }\end{array}$ & $\begin{array}{l}\text { } 5 \text { year cumulative } \\
\text { excess mortality: } \\
\text { o Drain group: } \\
10.2 \% \\
\text { o No drain group: } \\
22.4 \%\end{array}$ \\
\hline $\begin{array}{l}\text { Present } \\
\text { study }\end{array}$ & Finland & 1990-2015 & 1133 & 73 (22-99) & $4.8(2-27)$ & 9.5 & 13.7 & $\begin{array}{l}\text { The population of } \\
\text { Pirkanmaa region } \\
\text { stratified by sex, } \\
\text { age, and calendar } \\
\text { year (Statistics } \\
\text { Finland) }\end{array}$ & $\begin{array}{l}\text { - Cumulative excess } \\
\text { mortality: } \\
\text { o } 1 \text { year: } 9 \% \\
\text { o } 5 \text { years: } 18 \% \\
\text { o } 10 \text { years: } 27 \% \\
\text { o } 15 \text { years: } 37 \% \\
\text { o } 20 \text { years: } 48 \%\end{array}$ \\
\hline
\end{tabular}

$\mathrm{CSDH}=$ chronic subdural hematoma; N/A = not available

needing re-operation within 2 years of the original operation. All patients were followed until death or the end of year 2017.

\section{Survival analysis}

The variables chosen for survival analysis were sex, age groups, and variables known to be CSDH risk factors (trauma, chronic alcohol abuse, and antithrombotic medication). The effect of neurological condition, treatment group (operative versus non-operative), and hematoma recurrence were analyzed.

\section{Statistical analyses}

SPSS (IBM SPSS Statistics for Windows, Version 25.0, Armonk, NY, USA) was used for data analyses. Survival analyses were conducted using the statistical software R (version 3.6.0) with popEpi package (version 0.4.7). Descriptive statistics [frequency $(n)$, percentage, median, interquartile range, range] were used to describe variable and subgroup characteristics. The Chi square test was used to compare differences between groups. The statistical significance level was set at $p<0.05$. 
The cumulative relative survival ratio (CRSR) summarizes patients' excess risk of death due to the disease by comparing the survival of patients to that of the matched general population (the population of Pirkanmaa region stratified by sex, age, and calendar year). CRSRs were estimated by using the Ederer II method [13, 34]. To compare differences in relative survival adjusted for age, sex, and follow-up time, we estimated relative excess risk (RER) of death by using Poisson regression [10]. Each model included sex, age at diagnosis (4 groups: $0-59,60-69,70-79$, and $80+$ years), and 5 intervals of follow-up time after diagnosis ( 0 to $<1$ year, 1 to $<5$ years, and three 5 -year intervals from 5 to 20 years) in addition to a risk factor.

\section{Data availability statement}

The data that support the findings of this study are available from the corresponding author upon reasonable request.

\section{Results}

\section{Characteristics}

A total of 1133 patients with CSDH were identified, 736 (65\%) were men. The median age for CSDH diagnosis was 76 years, and women were older than men ( 79 vs. 75 years). Median follow-up time was 4.8 years, with a minimum of 0 days and maximum of 27 years. Median follow-up time for survivors was 6.6 years, with a minimum of 2 years. No patients were lost from follow-up.

Of all the patients, 965 (85\%) were operated. The indication for surgery was based on imaging and symptoms attributable to the mass effect of the hematoma. Operatively treated patients were slightly younger than non-operatively treated (median age 76 vs. 79 years, $p=0.001$ ). At least one comorbidity was reported by $82 \%$ of the patients in both treatment groups. Antithrombotic medication was used by $42 \%$ of the patients. Two or more comorbidities were reported by $38 \%$ of operative group patients and $48 \%$ of non-operative group patients $(p=0.015)$, three or more by $13 \%$ and $15 \%(p=0.052)$, respectively. Non-operatively treated CSDH patients more often had previously diagnosed dementia $(16 \%$ vs. $8 \%, p=$ 0.001 ). The overall prevalence of dementia in CSDH patients aged 70 years or older was $12 \%$. Significant differences were also noted in admission mRS; operatively treated patients had worse neurological disability [mRS scores of 4-5 were found in $52 \%$ of the operative group $(n=506 / 965)$ versus $28 \%$ of the non-operative group $(n=47 / 168), p<0.001]$. Operatively treated patients more often had headache or localizing neurological deficits. The characteristics of the entire sample and treatment subgroups are presented in Table 2. We have previously published the details of CSDH patients from this same patient cohort stratified by gender, age groups, and time periods [32].

Most operations used local anesthesia $(n=828 ; 86 \%)$ via one burr hole, and the hematoma was removed through irrigation. A subdural drain was inserted in 59 patients $(6 \%)$. The drain was kept below the head level with no suction for 24 $48 \mathrm{~h}$. Subgaleal drains were not used. Only one patient underwent craniotomy as the primary surgery. The patients were actively mobilized directly after the operation. Recurrent hematoma was treated surgically for 273 cases (28\%, median age 76 years). The reason for non-operative treatment for majority of the cases was that the CSDH did not cause neurological signs or significant symptoms. Only 7 patients were not offered surgery because they presented in a moribund state, and the analyses have been done also by excluding these patients. Most non-operatively treated patients were not admitted to a neurosurgical clinic. Non-operative treatment included discontinuation of possible antithrombotic medication, active mobilization, and follow-up CT-scans (routinely or for emerging new symptoms).

\section{Mortality after diagnosis of CSDH}

By the end of the follow-up period, 710 (63\%) of the 1133 patients had died, 449 of men (61\%), and 261 of women (66\%). Median age at death was 84 years (IQR 76-89 years), 83 years for men, and 86 years for women. Similarly, the median age at death was 84 years in the operative group and 85 years in the non-operative group. The 30-day and 6-month mortalities after diagnosis of CSDH were $3 \%$ and $10 \%$, respectively. The overall 1-year and 2-year mortality rates were $14 \%$ and $22 \%$, respectively. There was no significant difference in mortality between men and women. One-year mortality was $12 \%$ in the operative group $(n=965)$ and $21 \%$ in the non-operative group $(n=168 ; p=0.003)$. After the patients $(n=7)$ who were not offered surgery, because they presented in a moribund state, were withdrawn from the non-operative group, the non-operative 1-year mortality was $18 \%$ (operative vs. non-operative: $p=0.053$ ). One-year mortality was $5 \%$ among the patients under the age of 60 , and $22 \%$ among those aged 80 and older $(p<0.001)$. A subgroup of patients with no comorbidities had a 1-year mortality of only $3 \%(n=206$, median age 72 years, IQR 61-78 years). Mortality rates are presented in Table 3. For comparison, the reference group mortality rates also are reported in Table 3.

\section{Long-term excess mortality}

The 1-year cumulative relative survival ratio (CRSR) for all CSDH patients was 0.91 (95\% CI 0.89-0.94), implying 9\% excess mortality compared with the matched general population. The cumulative excess mortality was $18 \%$ in 5 years (CRSR 0.82 ; 95\% CI $0.78-0.86$ ), $27 \%$ in 10 years (CRSR 
Table 2 Characteristics of all chronic subdural hematoma patients and treatment subgroups

\begin{tabular}{|c|c|c|c|c|c|c|c|}
\hline & \multicolumn{2}{|c|}{$\begin{array}{l}\text { Total sample } \\
n=1133\end{array}$} & \multicolumn{2}{|c|}{$\begin{array}{l}\text { Non-operative } \\
\text { treatment } n=168\end{array}$} & \multicolumn{2}{|c|}{$\begin{array}{l}\text { Operative } \\
\text { treatment } \\
n=965\end{array}$} & \multirow[t]{2}{*}{$p$ value } \\
\hline & $n$ & $\%$ & $n$ & $\%$ & $n$ & $\%$ & \\
\hline Median age, years, IQR & 76 & $67-83$ & 79 & $68-86$ & 76 & $66-82$ & 0.001 \\
\hline \multicolumn{8}{|l|}{ Sex } \\
\hline Men & 736 & 65.0 & 102 & 60.7 & 634 & 65.7 & 0.21 \\
\hline Traumatic etiology & 672 & 59.3 & 107 & 63.7 & 565 & 58.5 & 0.21 \\
\hline \multicolumn{8}{|l|}{ Comorbidity } \\
\hline Cardiovascular disease & 644 & 56.8 & 96 & 57.1 & 548 & 56.8 & 0.93 \\
\hline Diabetes & 178 & 15.7 & 27 & 16.1 & 151 & 15.6 & 0.89 \\
\hline Chronic alcohol abuse & 126 & 11.1 & 20 & 11.9 & 106 & 11.0 & 0.73 \\
\hline Cerebrovascular disease & 124 & 10.9 & 24 & 14.3 & 100 & 10.4 & 0.13 \\
\hline Dementia & 99 & 8.8 & 26 & 15.7 & 73 & 7.6 & 0.001 \\
\hline Pulmonary disease & 68 & 6.0 & 16 & 9.5 & 52 & 5.4 & 0.05 \\
\hline Epilepsy & 32 & 2.8 & 3 & 1.8 & 29 & 3.0 & 0.38 \\
\hline Neurodegenerative disease & 20 & 1.8 & 7 & 4.2 & 13 & 1.3 & 0.01 \\
\hline Hydrocephalus & 9 & 0.8 & 0 & 0 & 9 & 0.9 & 0.21 \\
\hline \multicolumn{8}{|l|}{ Medication } \\
\hline Antiplatelet & 268 & 23.7 & 36 & 21.4 & 232 & 24.0 & 0.46 \\
\hline Warfarin & 187 & 16.5 & 26 & 15.5 & 161 & 16.7 & 0.69 \\
\hline Warfarin AND antiplatelet & 23 & 2.0 & 2 & 1.2 & 21 & 2.2 & 0.40 \\
\hline \multicolumn{8}{|l|}{ Admission GCS } \\
\hline $13-15$ & 1007 & 88.9 & 157 & 93.5 & 850 & 88.1 & 0.04 \\
\hline $9-12$ & 91 & 8.0 & 8 & 4.8 & 83 & 8.6 & 0.91 \\
\hline $3-8$ & 35 & 3.1 & 3 & 1.8 & 32 & 3.3 & 0.29 \\
\hline Admission mRS 0-3 & 580 & 51.2 & 121 & 72.0 & 459 & 47.6 & $<0.001$ \\
\hline \multicolumn{8}{|l|}{ Symptoms } \\
\hline Hemiparesis & 444 & 39.2 & 9 & 5.4 & 435 & 45.1 & $<0.001$ \\
\hline Vertigo or postural instability & 408 & 36.0 & 35 & 20.8 & 373 & 38.7 & $<0.001$ \\
\hline Disorientation/memory impairment & 390 & 34.4 & 54 & 32.1 & 336 & 34.8 & 0.50 \\
\hline General malaise & 367 & 32.4 & 50 & 29.8 & 317 & 32.8 & 0.43 \\
\hline Headache & 340 & 30.0 & 28 & 16.7 & 312 & 32.3 & $<0.001$ \\
\hline Aphasia & 245 & 21.6 & 9 & 5.4 & 236 & 24.5 & $<0.001$ \\
\hline Seizure & 117 & 10.3 & 28 & 16.7 & 89 & 9.2 & 0.003 \\
\hline Nausea and/or vomiting & 60 & 5.3 & 7 & 4.2 & 53 & 5.5 & 0.48 \\
\hline
\end{tabular}

IQR Interquartile range; GCS Glasgow Coma Scale; $m R S$ Modified Rankin Scale
$0.73 ; 95 \%$ CI $0.67-0.80$ ), $37 \%$ in 15 years (CRSR $0.63 ; 95 \%$ CI $0.54-0.73$ ), and $48 \%$ in 20 years (CRSR 0.52 ; 95\% CI $0.40-0.66)$. The excess mortality rate was highest during the first year of follow-up after diagnosis of CSDH, and it was 2$4 \%$ per year during the rest of the follow-up period. The excess mortality seemed to be more pronounced in women, but the difference was not statistically significant. CSDH patients had excess mortality in every age group, and it was more pronounced in the age group of $\geq 80$ years and in the nonoperatively treated patients. A subgroup of patients with no comorbidities had better survival than the matched general population. The CRSR with $95 \%$ confidence intervals are shown in Fig. 1.

\section{Relative excess risk of death}

In the age-, gender-, and follow-up time-adjusted regression model for RER, excess mortality was significantly related to (i) poor mRS 4-5 $(\mathrm{RER}=4.93)$ at admission and especially (ii) at discharge $(\mathrm{RER}=8.31)$, (iii) chronic alcohol abuse (RER $=4.47$ ), (iv) warfarin medication $(\mathrm{RER}=2.94)$, (v) age $\geq 80$ years old $(\mathrm{RER}=1.83)$, (vi) non-operative treatment 


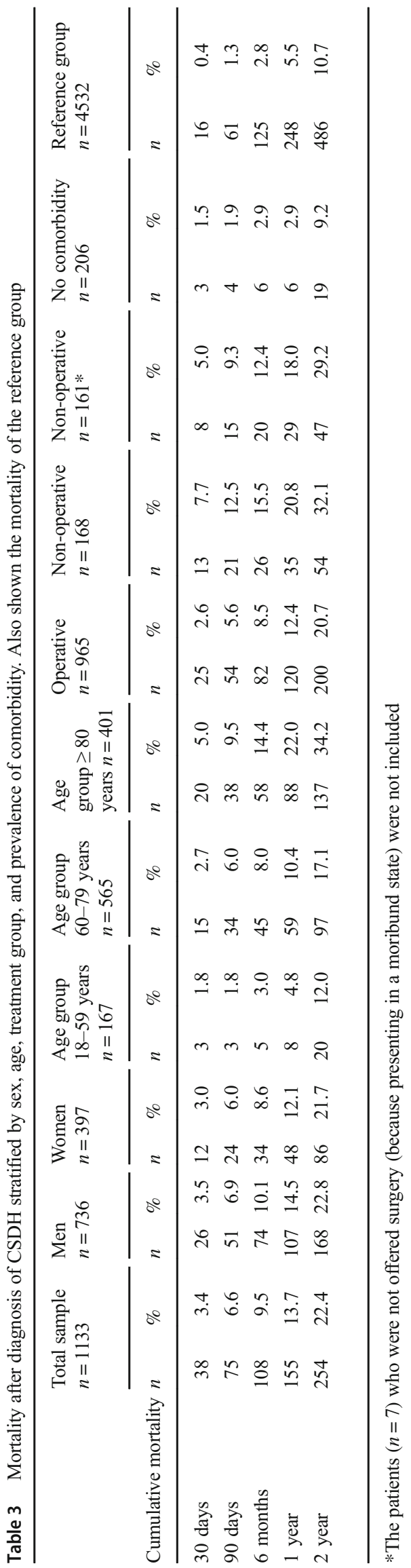

(RER $=1.56$; moribund patients $n=7$ excluded), and (vii) non-traumatic etiology $(\mathrm{RER}=1.69)$. Hematoma localization (unilateral/bilateral), thickness, or recurrence were not related to the excess mortality. Detailed RER results are presented in Table 4.

\section{Causes of death after CSDH}

The most frequent causes of death for women were dementia (29\%), ischemic cardiac disease (15\%), and cerebral ischemia (12\%), and the most common causes for men were ischemic cardiac disease (23\%), dementia (16\%), and cancer (14\%). SDH (the hematoma type (chronic, subacute, acute) could not be verified due to the nature of the cause of death data) was the cause of death in $42 / 710$ patients $(6 \%)$. In the matched reference group $(n=4532)$, the most common causes of death were ischemic cardiac disease (25\%; women $22 \%$ and men $26 \%$ ), cancer (19\%; women $15 \%$ and men $22 \%$ ), and dementia (15\%; women $18 \%$ and men $13 \%)$. As a cause of death, dementia was more common in patients with $\mathrm{CSDH}$ than in the reference group ( $21 \%$ vs. $15 \%, p<0.001)$. The difference was significant for women ( $29 \%$ vs. $18 \%, p<0.001)$, but not for men $(16 \%$ vs. $13 \%, p=0.12)$. The cause of death was traumatic in $11 \%$ of the CSDH patients, and 3\% in the reference group $(p<0.001)$. SDH was the cause of death in $6 \%$ and in $0.5 \%$, respectively $(p<0.001)$. Causes of death among the $\mathrm{CSDH}$ patients and the reference group are presented in Table 5. When stratifying the causes of death by survival time, the incidence of trauma-related death was significantly higher among CSDH patients compared with the reference group during the first 5 years $(p<0.001)$. In contrast, the incidence of dementia as the cause of death was higher among CSDH patients compared with the reference group after the first year, and increased over time reaching statistical difference from 1 to 10 years $(p<0.001$; Fig. 2$)$.

\section{Discussion}

\section{Summary of the key findings}

In our large population-based cohort, patients with CSDH had excess mortality, which increased over time from $9 \%$ at 1 year to $48 \%$ at 20 years after CSDH diagnosis. A subgroup of patients with no comorbidities had no excess mortality. The most important factors related to excess mortality were neurological disability at admission and at discharge. Age over 80 years almost doubled, warfarin almost tripled, and chronic alcohol abuse almost quintupled the risk of death after CSDH. Hematoma localization (unilateral/bilateral) or thickness were not relative risk factors nor was hematoma recurrence. In the median follow-up time of 4.8 years, there were 710 deaths, of which $6 \%$ were caused by SDH. The most common cause of 
Fig. 1 Excess mortality of chronic subdural hematoma patients. Cumulative relative survival ratios (with 95\% confidence intervals) illustrating excess mortality of the CSDH patients compared with the matched general population; entire cohort (a), stratified by age groups (b), by prevalence of comorbidity (c), and by treatment group. The horizontal line at 1.0 represents the survival of the matched general population and curves below that line represent excess mortality of the study population. The vertical line shows follow-up time (years)
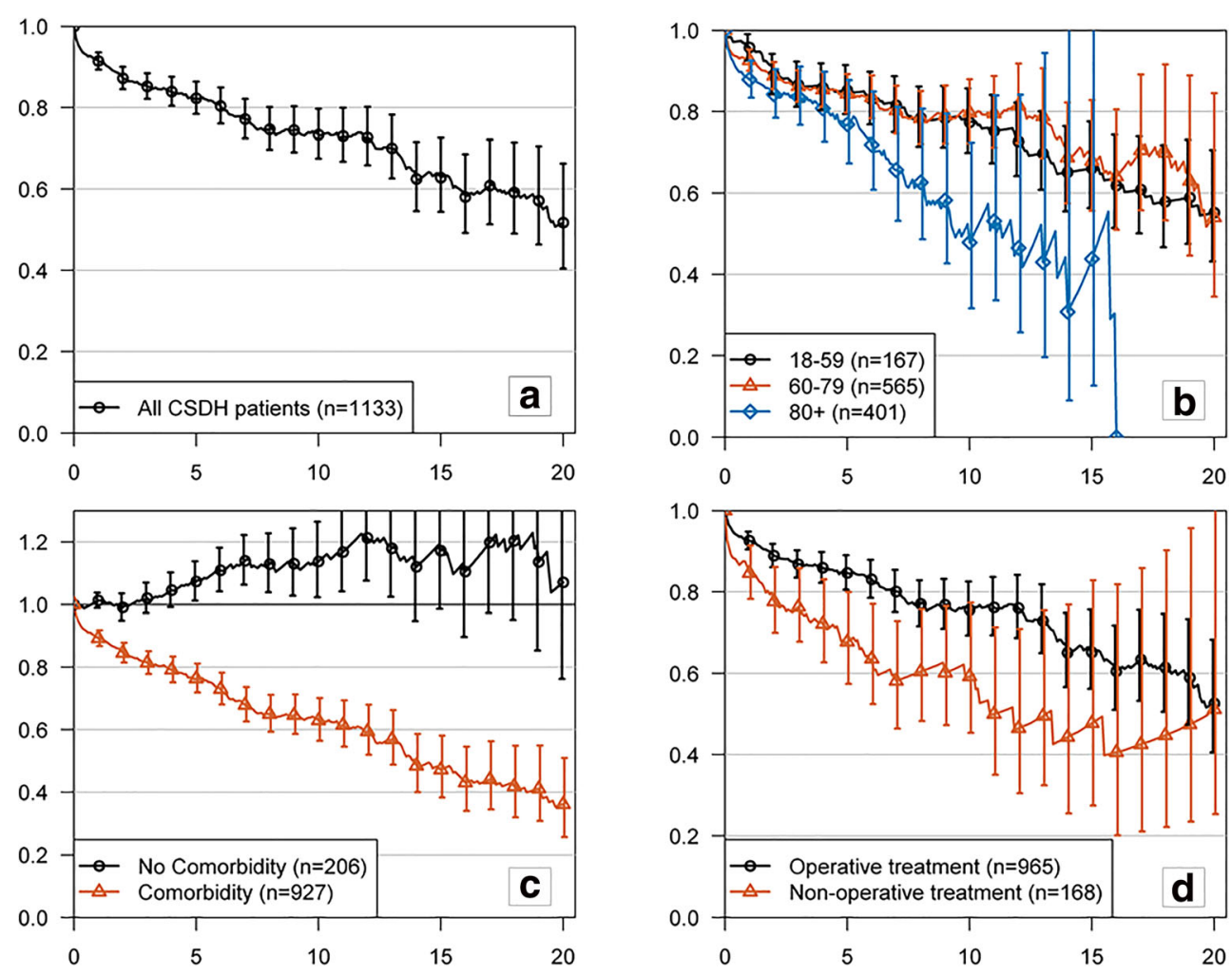

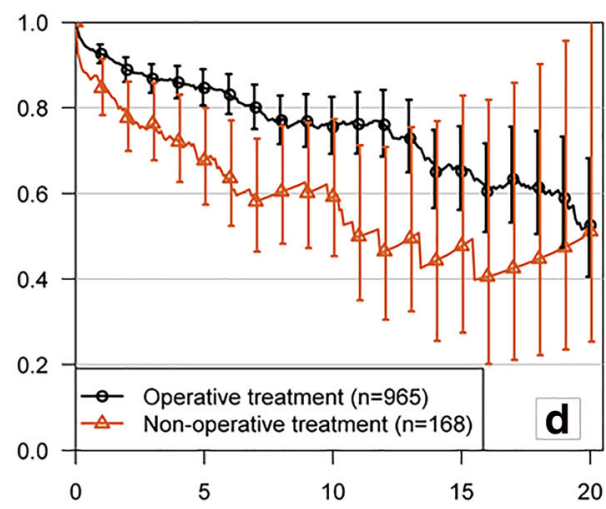

death was dementia, which was significantly more common as a cause of death among the CSDH patients than in the reference group. As a cause of death, dementia occurred later in CSDH patients than in the reference group.

\section{Comparison of the current findings to prior literature}

Miranda et al. observed excess mortality up to 1 year beyond diagnosis, but after that, life expectancy was equivalent with the general population [29]. Treatment group, size or laterality of subdural hematoma, and antithrombotic medication use were not associated with the mortality rate. Dumont and colleagues showed that patients with $\mathrm{CSDH}$ had worse survival than expected in every age group, and patients undergoing surgical drainage of CSDH (median survival 5.5 years) had significantly longer survival compared with patients not undergoing surgical drainage (2.3 years) [11]. The authors speculated that there can be selection bias, because the patients most likely to improve from surgery were offered surgical treatment. Mortality after CSDH was highest in the oldest patients over 85 years old, but the standardized mortality ratio was lower than in any other age group. Manickam et al. reported excess mortality continuing throughout a prolonged follow-up (median 5.2 years) as peers lived 12.4 years longer [25]. A prospective, randomized study by Santarius et al. revealed that among operatively treated patients, CSDH drainage significantly reduced 6-month mortality from 18 to $9 \%$ [33]. Additionally, a recent 5-year follow-up analysis of the aforementioned study showed a significant survival advantage for drainage as the relative survival in the no drain group was $77.6 \%$ compared with $89.8 \%$ in the drain group [16].

In our study, CSDH patients had excess mortality in every age group. The excess mortality was more pronounced in the age group of $\geq 80$ years. The risk of excess mortality was higher in the non-operative group than in the operative group (RER 1.56) even though the neurological condition at admission was better among non-operatively treated patients, and they were not predisposed to surgical complications. The reason behind this is probably that the burden of comorbidities was somewhat higher among non-operatively treated patients.

In contrast to the study by Santarius, CSDH recurrence was not a risk factor for excess mortality among our study patients. In fact, the patients with recurrence had a lower mortality at least during the first 2 years. We speculate that this might be explained by more frequent medical attention (follow-ups and re-operations) for patients that are in better general health before their first CSDH. Patients with more comorbidities are less likely to undergo a second operation. Even so, our 6month overall mortality rate $(10 \%)$ was comparable with the findings by Santarius and colleagues [33]. Also, our relative survival at 5 years was similar $(82 \%)$ than analyzed by Guilfoyle [16]. The mortality differences between studies are most likely due to differences in case ascertainment, healthcare systems, and population-related life expectancies.

Our study is in line with the previous studies demonstrating that neurological disability at discharge is strongly associated 
Table 4 Relative excess risk of death (RER) estimates and 95\% confidence intervals for each subgroup of the 1133 chronic subdural hematoma patients adjusted for age, gender, and follow-up time

\begin{tabular}{|c|c|c|c|c|}
\hline & \multicolumn{2}{|c|}{ Total sample $n=1133$} & \multirow[t]{2}{*}{ RER } & \multirow[t]{2}{*}{$95 \% \mathrm{CI}$} \\
\hline & $\mathrm{n}$ & $\%$ & & \\
\hline \multicolumn{5}{|l|}{ Sex } \\
\hline Men & 736 & 65.0 & 1 & Ref \\
\hline Women & 397 & 35.0 & 1.17 & $0.82-1.65$ \\
\hline \multicolumn{5}{|l|}{ Age at CSDH diagnosis, years } \\
\hline $18-59$ & 167 & 14.7 & 1 & Ref \\
\hline $60-79$ & 565 & 49.9 & 1.05 & $0.68-1.61$ \\
\hline$\geq 80$ & 401 & 35.4 & 1.83 & $1.11-3.02$ \\
\hline \multicolumn{5}{|l|}{ Chronic alcohol abuse } \\
\hline No & 1007 & 88.9 & 1 & Ref \\
\hline Yes & 126 & 11.1 & 4.47 & $2.88-6.95$ \\
\hline \multicolumn{5}{|l|}{ Traumatic etiology } \\
\hline Yes & 672 & 59.3 & 1 & Ref \\
\hline No & 461 & 40.7 & 1.69 & $1.20-2.38$ \\
\hline \multicolumn{5}{|l|}{ Antithrombotic medication } \\
\hline None & 655 & 57.8 & 1 & Ref \\
\hline Antiplatelet & 268 & 23.7 & 1.20 & $0.72-2.01$ \\
\hline Warfarin & 187 & 16.5 & 2.94 & $1.91-4.54$ \\
\hline Warfarin AND antiplatelet & 23 & 2.0 & 3.24 & $1.35-7.75$ \\
\hline \multicolumn{5}{|l|}{ Admission GCS } \\
\hline $13-15$ & 1007 & 88.9 & 1 & Ref \\
\hline $9-12$ & 91 & 8.0 & 3.53 & $2.35-5.32$ \\
\hline $3-8$ & 35 & 3.1 & 5.71 & $3.47-9.41$ \\
\hline \multicolumn{5}{|l|}{ Admission mRS } \\
\hline $0-3$ & 580 & 51.2 & 1 & Ref \\
\hline $4-5$ & 553 & 48.8 & 4.93 & $3.12-7.80$ \\
\hline \multicolumn{5}{|l|}{ Hematoma localization } \\
\hline Unilateral & 876 & 77.3 & 1 & Ref \\
\hline Bilateral & 257 & 22.7 & 0.74 & $0.46-1.18$ \\
\hline \multicolumn{5}{|c|}{ Hematoma thickness, mm (missing $n=23$ ) } \\
\hline$\leq 15 \mathrm{~mm}$ & 376 & 33.2 & 1 & Ref \\
\hline $16-25$ & 474 & 41.8 & 0.69 & $0.48-1.01$ \\
\hline$>25$ & 260 & 22.9 & 0.59 & $0.34-1.01$ \\
\hline \multicolumn{5}{|l|}{ Operative treatment } \\
\hline Yes & 965 & 85.2 & 1 & Ref \\
\hline No & 168 & 14.8 & 1.77 & $1.18-2.65$ \\
\hline $\mathrm{No}^{1}$ & 161 & 14.2 & 1.56 & $1.01-2.41$ \\
\hline \multicolumn{5}{|l|}{ Discharge $\mathrm{GCS}^{2}$} \\
\hline $13-15$ & 942 & 97.6 & 1 & Ref \\
\hline $9-12$ & 9 & 0.9 & 14.84 & $6.64-33.18$ \\
\hline $3-8$ & 14 & 1.5 & 98.30 & $39.35-245.56$ \\
\hline \multicolumn{5}{|l|}{ Discharge $\mathrm{mRS}^{2}$} \\
\hline $0-3$ & 727 & 75.3 & 1 & Ref \\
\hline $4-5$ & 238 & 24.7 & 8.31 & $5.48-12.58$ \\
\hline \multicolumn{5}{|l|}{ Recurrent hematoma ${ }^{2}$} \\
\hline No & 692 & 71.7 & 1 & Ref \\
\hline Yes & 273 & 28.3 & 0.78 & $0.48-1.26$ \\
\hline
\end{tabular}

RER Relative excess risk of death, CI Confidence interval, Ref Reference, GCS Glasgow Coma Scale score, $m R S$ Modified Rankin Scale score

${ }^{1}$ The patients $(n=7)$ who were not offered surgery because they presented in a moribund state were not included

${ }^{2}$ Includes only operatively treated patients

to long-term survival [11, 25, 29]. This is no surprise because it correlates to functional status, which has been recognized to have a great impact on life expectancy in general [20].
However, it is difficult to differentiate the effects of underlying comorbidities from the effects of CSDH on long-term survival. A subgroup of patients $(n=206)$ with no comorbidities 
survived better than the matched general population. In addition, hematoma bilaterality, thickness, or recurrence were not relative risk factors. Accordingly, even a large recurring CSDH may not affect the long-term survival by itself. Therefore, the patient-related variables are probably more important than the CSDH itself. Based on this data, it seems likely that the comorbidities are the cause of excess mortality rather than CSDH itself. Some patients are frail due to ageassociated brain atrophy and other comorbidities, and CSDH seems to be a sentinel health event, a harbinger of subsequent morbidity and mortality, for this group of patients [3, 11, 29]. In contrast, patients with no comorbidities are probably healthier than the matched general population.

Hence, the excess mortality after diagnosis of CSDH might be reduced by more assertively treating the comorbidities, of which the most common were vascular diseases, diabetes, and chronic alcohol abuse. It is also known, that the hospitalization of older people decreases daily living functioning [7]. For this reason, it has been proposed that already perioperative care should be optimized by a multidisciplinary approach and by promoting early rehabilitation [35].

Antithrombotic drug use is common among CSDH patients and is speculated to attribute to the greater incidence of CSDH among elderly $[6,8,15,23,30]$. In our study, the use of warfarin, but not the use of antiplatelets, was a relative risk factor for excess mortality. This could reflect the increased risks of warfarin in the context of CSDH or be explained by the fact that the baseline diseases treated with antiplatelet drugs are not as severe as with warfarin. Similarly, chronic alcohol abuse was a relative risk factor for excess mortality after CSDH, but it is a risk factor for excess mortality also independently $[9,36]$. Moreover, non-traumatic etiology was a relative risk factor for excess mortality among CSDH patients. This could be at least partly explained by the more common use of antithrombotic medication by patients with non-traumatic than traumatic etiology (47\% vs. $39 \%)$, and the underlying medication-suggesting comorbidities. Additionally, CSDH might be a manifestation of degenerative or inflammatory disease rather than trauma [14]. In other words, aging, longstanding and ongoing alcohol abuse, and worse baseline general and neurological health all appear to contribute to greater mortality following $\mathrm{CSDH}$.

The most important reason for the greater incidence of CSDH among the elderly has been speculated to be attributed to brain atrophy [22, 24, 37]. Dementia has been linked to brain atrophy [5]. At the time of diagnosis of $\mathrm{CSDH}$, the prevalence of dementia in our CSDH patients (12\% in patients aged 70 years or older) was similar as the prevalence in

Table 5 The causes of death until the end of 2017 of the 1133 patients with chronic subdural hematomas between 1990 and 2015 in Pirkanmaa, Finland. The causes of death in the matched reference group between 1990 and 2015 are presented for comparison

\begin{tabular}{|c|c|c|c|c|c|c|c|c|c|c|c|c|}
\hline & \multicolumn{2}{|c|}{$\begin{array}{l}\text { Total sample } \\
n=1133\end{array}$} & \multicolumn{2}{|c|}{ Men $n=736$} & \multicolumn{2}{|c|}{$\begin{array}{l}\text { Women } \\
n=397\end{array}$} & \multicolumn{2}{|c|}{$\begin{array}{l}\text { Operative } \\
\text { treatment } \\
n=965\end{array}$} & \multicolumn{2}{|c|}{$\begin{array}{l}\text { Non-operative } \\
\text { treatment } n=168\end{array}$} & \multicolumn{2}{|c|}{$\begin{array}{l}\text { Causes of death in the } \\
\text { matched reference group } \\
n=4532\end{array}$} \\
\hline & $n$ & $\%$ & $n$ & $\%$ & $n$ & $\%$ & $n$ & $\%$ & $n$ & $\%$ & $n$ & $\%$ \\
\hline Age, years (median, IQR) & 76 & $67-83$ & 75 & $65-81$ & 79 & $70-85$ & 76 & $66-82$ & 79 & $68-86$ & 76 & $67-83$ \\
\hline \multicolumn{13}{|l|}{ Follow-up time, years } \\
\hline Median & 4.8 & & 5.1 & & 4.6 & & 5.2 & & 3.3 & & 6.4 & \\
\hline Range & $0-27$ & & $0-26$ & & $0-27$ & & $0-27$ & & $0-21$ & & $0-28$ & \\
\hline No. of deaths & 710 & 62.7 & 449 & 61.0 & 261 & 65.7 & 609 & 62.3 & 101 & 60.1 & 1918 & 42.3 \\
\hline Age at death, median, IQR & 84 & $76-89$ & 83 & $74-88$ & 86 & $80-91$ & 84 & $76-89$ & 85 & $79-90$ & 84 & $78-88$ \\
\hline Ischemic cardiac disease & 143 & 20.1 & 103 & 22.9 & 40 & 15.3 & 122 & 20.0 & 21 & 20.8 & 473 & 24.7 \\
\hline Cerebrovascular disease & 90 & 12.7 & 54 & 12.0 & 36 & 13.8 & 80 & 13.1 & 10 & 9.9 & 216 & 11.3 \\
\hline Cerebral hemorrhage & 18 & 2.5 & 13 & 2.9 & 5 & 1.9 & 13 & 2.1 & 5 & 5.0 & 23 & 1.2 \\
\hline Cerebral ischemia & 72 & 10.1 & 41 & 9.1 & 31 & 11.9 & 67 & 11.0 & 5 & 5.0 & 167 & 8.7 \\
\hline Cancer & 91 & 12.8 & 64 & 14.3 & 27 & 10.3 & 80 & 13.1 & 11 & 10.9 & 370 & 19.3 \\
\hline Dementia and Alzheimer's disease & 146 & 20.6 & 70 & 15.6 & 76 & 29.1 & 121 & 19.9 & 25 & 24.8 & 278 & 14.5 \\
\hline Pulmonary disease & 34 & 4.8 & 24 & 5.3 & 10 & 3.8 & 29 & 4.8 & 5 & 5.0 & 119 & 6.2 \\
\hline Pneumonia & 16 & 2.3 & 9 & 2.0 & 7 & 2.7 & 15 & 2.5 & 1 & 1.0 & 45 & 2.3 \\
\hline Trauma & 75 & 10.6 & 50 & 11.1 & 25 & 9.6 & 65 & 10.7 & 10 & 9.9 & 58 & 3.0 \\
\hline Accidental falls & 41 & 5.8 & 25 & 5.6 & 16 & 6.1 & 36 & 5.9 & 5 & 5.0 & 33 & 1.7 \\
\hline Subdural hematoma, traumatic & 38 & 5.4 & 25 & 5.6 & 13 & 5.0 & 33 & 5.4 & 5 & 5.0 & 9 & 0.5 \\
\hline Subdural hematoma, non-traumatic & 4 & 0.6 & 4 & 0.9 & 0 & & 3 & 0.5 & 1 & 1.0 & 1 & 0.05 \\
\hline Unknown & 0 & & 0 & & 0 & & 0 & & 0 & & 20 & 1.0 \\
\hline
\end{tabular}




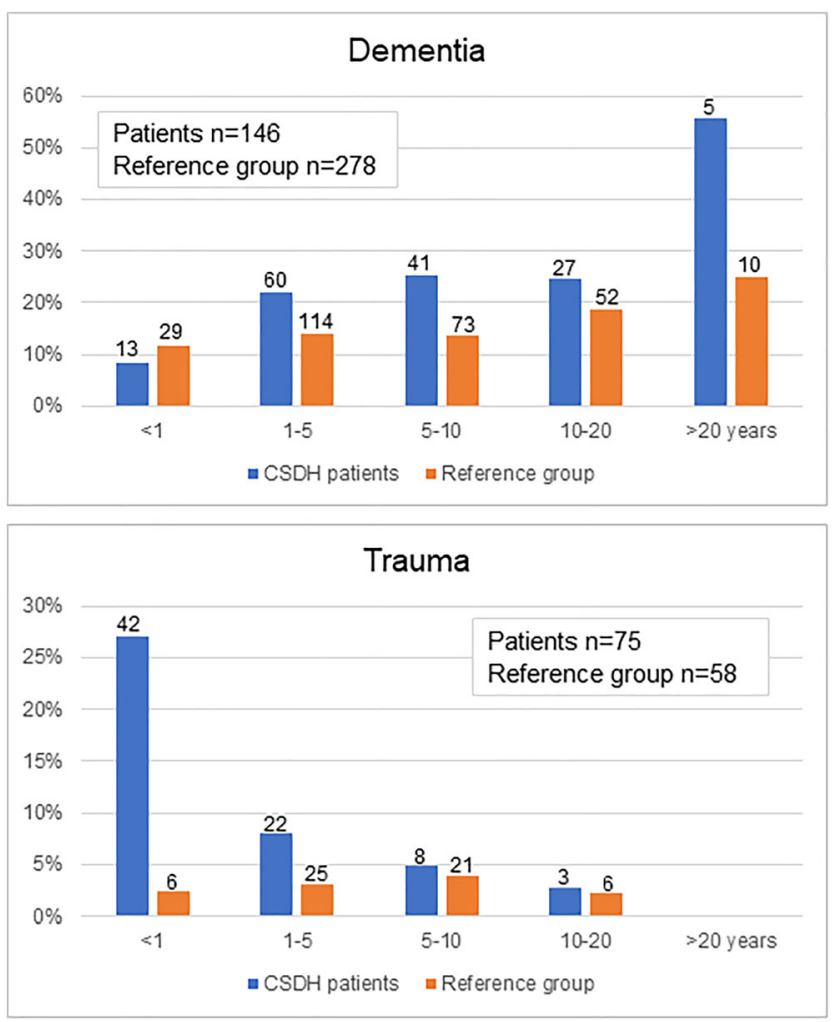

Fig. 2 Dementia and trauma as a cause of death stratified by survival time. The CSDH patients are compared with the matched reference group. The percentages represent all the deaths during the time period. The number of deaths 710 among CSDH patients, and 1918 among the reference group

Western Europe reported by the World Alzheimer report 2015 [31]. As a cause of death, dementia was more prevalent in patients with CSDH than in our reference group. The difference was seen after the first year and was more pronounced in the later years. Additionally, the excess mortality related to $\mathrm{CSDH}$ increases with time. Our results support the idea that CSDH may be a risk factor for dementia. This could be explained by Bin Zahid and colleagues' observation that CSDH is related to a significant increase in the degree of subsequent brain atrophy [4]. It seems that brain atrophy is a risk factor for $\mathrm{CSDH}$, which in turn accelerates neurodegeneration and increases the risk of dementia. Further long-term prospective studies are needed to verify this association.

\section{Strengths and limitations}

Our series represents the most extensive non-register-based study of consecutive CSDH cases treated in one neurosurgical department. Although retrospective in nature, the populationbased setting makes it less prone to selection bias. Moreover, all the data was collected by one of the authors (M.R.). Our study gives a reliable population-based estimate of the CSDHassociated excess mortality based on the comparison with a matched general population.
This study has several limitations. ICD-codes were used to retrospectively identify all the patients of interest. There is a possibility that some cases were not recognized due to incomplete or incorrect ICD-coding. It is likely that all the patients undergoing surgery were identified, but the ICD-coding can be incomplete among the non-operatively treated patients, as a neurosurgeon has only been consulted on these cases. Neuroimaging was not reviewed, and there can be inconsistencies in reporting the hematoma thickness. In addition, the distinction between subacute and chronic SDH is not always obvious, both in relation to time and neuroradiological characteristics. No definition of CSDH is universally accepted [18]. Subacute SDHs were excluded from this study, because this hematoma subtype is considered to represent an entity of its own $[2,12,21]$. Additionally, autopsies were not performed on all of the deceased patients, and some of the causes of deaths might not be correct. Also, adjustments to the statistical analyses were limited because we did not have access to comorbidity data from the matched general population. However, it is reasonable to assume that controls and patients had similar comorbidities.

Future CSDH research should focus on preventive measures that take into account prior health conditions and fallrelated injury risk factors that predispose to CSDH. Frailty, functionality, dependency, and comorbidity should be of special interest as these issues are prognosticators of general disability, hospital readmission, and mortality.

\section{Conclusions}

Patients with CSDH have long-term excess mortality, which is evident up to at least 20 years after diagnosis. Patient-related characteristics, especially chronic alcohol abuse, antithrombotic medication use, and neurological disability both at admission, and at discharge, have a strong association with excess mortality, whereas specific CSDH-related findings do not. A subgroup of patients with no comorbidities had no excess mortality. The most common cause of death was dementia, which was more common as a cause of death in patients with CSDH than in the reference group after the first year. Consequently, there can be a two-way correlation between CSDH and dementia.

Funding information Pirkanmaa Hospital District and the Maire Taponen Foundation provided financial support in the form of a personal research scholarship (M.R.).

\section{Compliance with ethical standards}

Conflict of interest Dr. Luoto has received funding from the Government's Special Financial Transfer tied to academic research in Health Sciences (Finland), the Emil Aaltonen Foundation, and Finnish Medical SocietyDuodecim. Dr. Iverson acknowledges unrestricted 
philanthropic support from the Mooney-Reed Charitable Foundation, Heinz Family Foundation, ImPACT Applications, Inc., and Spaulding Research Institute. He serves as a strategic scientific advisor for BioDirection, Inc. The other authors report nothing to disclose.

Ethical approval All procedures performed in studies involving human participants were in accordance with the ethical standards of the institutional and/or national research committee (the Ethics Committee of the Pirkanmaa Hospital District, approval code R12082) and with the 1964 Helsinki declaration and its later amendments or comparable ethical standards. All data was collected retrospectively without contacting the patients. For this type of study formal consent is not required.

Disclaimer The sponsors had no role in the design or conduct of this research.

Open Access This article is licensed under a Creative Commons Attribution 4.0 International License, which permits use, sharing, adaptation, distribution and reproduction in any medium or format, as long as you give appropriate credit to the original author(s) and the source, provide a link to the Creative Commons licence, and indicate if changes were made. The images or other third party material in this article are included in the article's Creative Commons licence, unless indicated otherwise in a credit line to the material. If material is not included in the article's Creative Commons licence and your intended use is not permitted by statutory regulation or exceeds the permitted use, you will need to obtain permission directly from the copyright holder. To view a copy of this licence, visit http://creativecommons.org/licenses/by/4.0/.

\section{References}

1. Adhiyaman V, Asghar M, Ganeshram KN, Bhowmick BK (2002) Chronic subdural haematoma in the elderly. Postgrad Med J 78:7175

2. Alves JL, Santiago JG, Costa G, Mota Pinto A (2016) A standardized classification for subdural hematomas- I. Am J Forensic Med Pathol 37:174-178

3. Bartek J Jr, Sjavik K, Stahl F, Kristiansson H, Solheim O, Gulati S, Sagberg LM, Forander P, Jakola AS (2017) Surgery for chronic subdural hematoma in nonagenarians: a Scandinavian populationbased multicenter study. Acta Neurol Scand 136:516-520

4. Bin Zahid A, Balser D, Thomas R, Mahan MY, Hubbard ME, Samadani U (2018) Increase in brain atrophy after subdural hematoma to rates greater than associated with dementia. J Neurosurg 19

5. Chapleau M, Aldebert J, Montembeault M, Brambati SM (2016) Atrophy in Alzheimer's disease and semantic dementia: an ALE meta-analysis of voxel-based morphometry studies. J Alzheimers Dis 54:941-955

6. Connolly BJ, Pearce LA, Hart RG (2014) Vitamin K antagonists and risk of subdural hematoma: meta-analysis of randomized clinical trials. Stroke 45:1672-1678

7. Covinsky KE, Palmer RM, Fortinsky RH, Counsell SR, Stewart AL, Kresevic D, Burant CJ, Landefeld CS (2003) Loss of independence in activities of daily living in older adults hospitalized with medical illnesses: increased vulnerability with age. J Am Geriatr Soc 51:451-458

8. De Bonis P, Trevisi G, de Waure C, Sferrazza A, Volpe M, Pompucci A, Anile C, Mangiola A (2013) Antiplatelet/ anticoagulant agents and chronic subdural hematoma in the elderly. PLoS One 8:e68732
9. Di Castelnuovo A, Costanzo S, Bagnardi V, Donati MB, Iacoviello L, de Gaetano G (2006) Alcohol dosing and total mortality in men and women: an updated meta-analysis of 34 prospective studies. Arch Intern Med 166:2437-2445

10. Dickman PW, Sloggett A, Hills M, Hakulinen T (2004) Regression models for relative survival. Stat Med 23:51-64

11. Dumont TM, Rughani AI, Goeckes T, Tranmer BI (2013) Chronic subdural hematoma: a sentinel health event. World Neurosurg 80: 889-892

12. Echlin F (1949) Traumatic subdural hematoma; acute, subacute and chronic; an analysis of 70 operated cases. J Neurosurg 6:294-303

13. Ederer F HH (1959) Instructions to IBM 650 programmers in processing survival computations. Methodological note no. 10. Bethesda, MD end results Eval sect Natl Cancer Inst 1959

14. Edlmann E, Giorgi-Coll S, Whitfield PC, Carpenter KLH, Hutchinson PJ (2017) Pathophysiology of chronic subdural haematoma: inflammation, angiogenesis and implications for pharmacotherapy. J Neuroinflammation 14:108-017-0881-y

15. Gaist D, Garcia Rodriguez LA, Hellfritzsch M, Poulsen FR, Halle B, Hallas J, Pottegard A (2017) Association of antithrombotic drug use with subdural hematoma risk. JAMA 317:836-846

16. Guilfoyle MR, Hutchinson PJ, Santarius T (2017) Improved longterm survival with subdural drains following evacuation of chronic subdural haematoma. Acta Neurochir 159:903-905

17. He W, Goodkind D, Kowal P (2016) U.S. Census Bureau, International Population Reports, P95/16-1, An Aging World: 2015. U.S. Government Publishing Office, Washington, DC

18. Iorio-Morin C, Touchette C, Levesque M, Effendi K, Fortin D, Mathieu D (2018) Chronic subdural hematoma: toward a new management paradigm for an increasingly complex population. J Neurotrauma 35:1882-1885

19. Jones S, Kafetz K (1999) A prospective study of chronic subdural haematomas in elderly patients. Age Ageing 28:519-521

20. Keeler E, Guralnik JM, Tian H, Wallace RB, Reuben DB (2010) The impact of functional status on life expectancy in older persons. J Gerontol A Biol Sci Med Sci 65:727-733

21. Kpelao E, Beketi KA, Moumouni AK, Doleagbenou A, Ntimon B, Egbohou P, Mouzou T, Tomta K, Sama DH, Abalo A, Walla A, Dossim A (2016) Clinical profile of subdural hematomas: dangerousness of subdural subacute hematoma. Neurosurg Rev 39:237240 discussion 240

22. Lee KS (2016) Chronic subdural hematoma in the aged, trauma or degeneration? J Korean Neurosurg Soc 59:1-5

23. Lindvall P, Koskinen LO (2009) Anticoagulants and antiplatelet agents and the risk of development and recurrence of chronic subdural haematomas. J Clin Neurosci 16:1287-1290

24. Liu H, Yang Y, Xia Y, Zhu W, Leak RK, Wei Z, Wang J, Hu X (2017) Aging of cerebral white matter. Ageing Res Rev 34:64-76

25. Manickam A, Marshman LA, Johnston R (2016) Long-term survival after chronic subdural haematoma. J Clin Neurosci 34:100104

26. Markwalder TM (1981) Chronic subdural hematomas: a review. J Neurosurg 54:637-645

27. Maurice-Williams RS (1999) Chronic subdural haematoma: an everyday problem for the neurosurgeon. Br J Neurosurg 13:547-549

28. Mehta V, Harward SC, Sankey EW, Nayar G, Codd PJ (2018) Evidence based diagnosis and management of chronic subdural hematoma: a review of the literature. J Clin Neurosci 50:7-15

29. Miranda LB, Braxton E, Hobbs J, Quigley MR (2011) Chronic subdural hematoma in the elderly: not a benign disease. $\mathrm{J}$ Neurosurg 114:72-76

30. Nathan S, Goodarzi Z, Jette N, Gallagher C, Holroyd-Leduc J (2017) Anticoagulant and antiplatelet use in seniors with chronic subdural hematoma: systematic review. Neurology 88:1889-1893

31. Prince M, Wimo A, Ali G, Wu Y, Prina M (2015) World Alzheimer Report 2015: the global impact of dementia: an analysis of 
prevalence, incidence, cost and trends. Alzheimer's Disease International, London

32. Rauhala M, Luoto TM, Huhtala H, Iverson GL, Niskakangas T, Ohman J, Helen P (2019) The incidence of chronic subdural hematomas from 1990 to 2015 in a defined Finnish population. J Neurosurg 1-11

33. Santarius T, Kirkpatrick PJ, Ganesan D, Chia HL, Jalloh I, Smielewski P, Richards HK, Marcus H, Parker RA, Price SJ, Kirollos RW, Pickard JD, Hutchinson PJ (2009) Use of drains versus no drains after burr-hole evacuation of chronic subdural haematoma: a randomised controlled trial. Lancet 374:1067-1073

34. Seppa K, Hakulinen T, Laara E, Pitkaniemi J (2016) Comparing net survival estimators of cancer patients. Stat Med 35:1866-1879

35. Shapey J, Glancz LJ, Brennan PM (2016) Chronic subdural haematoma in the elderly: is it time for a new paradigm in management? Curr Geriatr Rep 5:71-77
36. Whitfield JB, Heath AC, Madden PAF, Landers JG, Martin NG (2018) Effects of high alcohol intake, alcohol-related symptoms and smoking on mortality. Addiction 113:158-166

37. Yang AI, Balser DS, Mikheev A, Offen S, Huang JH, Babb J, Rusinek H, Samadani U (2012) Cerebral atrophy is associated with development of chronic subdural haematoma. Brain Inj 26:17311736

38. Yang W, Huang J (2017) Chronic subdural hematoma: epidemiology and natural history. Neurosurg Clin N Am 28:205-210

Publisher's note Springer Nature remains neutral with regard to jurisdictional claims in published maps and institutional affiliations. 